\title{
Problematizações, Desafios e Possibilidades da INSERÇão DA RELIGIOSIDADE/ESPIRITUALIDADE (R/E) NO CONTEXTO HOSPITALAR BRAsILEIRO
}

\author{
PROBLEMATIZATIONS, CHALLENGES AND POSSIBILITIES OF THE \\ INSERTION OF RELIGIOSITY/SPIRITUALITY (R/S) IN THE CONTEXT OF
}

BRAZILIAN HOSPITALS

\author{
TIAGO D'OLIVEIRA SILVA ${ }^{(*)}$ \\ LUCIANA FERNANDES MARQUES ${ }^{(\star *)}$
}

\begin{abstract}
RESUMO
O Brasil é um país reconhecidamente religioso e espiritualizado, embora os censos do IBGE de 1990, 2000 e 2010 tenham apontado aumento progressivo do número daqueles que se consideram sem religião. Em comparação com outros países, também o Brasil aparece como um país de predominância religiosa. Esses números revelam que a religião é um tema de interesse para o brasileiro, que atravessa a cultura e se faz presente no cotidiano influenciando suas crenças, comportamento e visão de mundo. A partir dessas constatações, pode-se inferir que a demanda para trabalhar as intersecções da R/E nos atendimentos de saúde pode ser maior do que o esperado e maior do que os profissionais de saúde estejam preparados para lidar. Pode-se indagar se esses profissionais têm algum aprendizado formal dentro das suas formações sobre o tema da R/E e o quanto estão receptivos para lidar com religiosidades/espiritualidades diferentes da sua e talvez desconhecidas, tendo em vista a diversidade religiosa no Brasil e até a multirreligiosidade (quando a pessoa frequenta mais de uma religião simultaneamente). $\mathrm{O}$ objetivo deste trabalho é problematizar o tema da Religiosidade e da Espiritualidade (R/E) na área da saúde, especialmente no contexto hospitalar brasileiro.
\end{abstract}

Palavras-Chave: Religiosidade/Espiritualidade. Contexto hospitalar. Profissionais de saúde. SUS. Brasil.

\begin{abstract}
Brazil is an admittedly religious and spiritual country, although the IBGE Census 1990, 2000 and 2010 have pointed progressive increase in the number of those who consider themselves non-religious. Compared to other countries, Brazil also appears as a country of religious dominance. These figures show that religion is a topic of interest to the Brazilian, who crosses culture and is present in everyday influencing their beliefs, behavior and world view. From these findings, it can be inferred that the demand to work the intersections of Religiosity and Spirituality $(R / E)$ in health care may be higher than expected and higher than the health professionals are prepared to handle. One can ask whether these professionals have some formal learning within their formations on the subject of $R / E$ and how much they are
\end{abstract}

\footnotetext{
(*) Graduado em Ciência da Computação (UFRGS, 2006), Graduando em Psicologia (UFRGS, 2010-2016), Mestrando pelo Programa de Pós-Graduação em Ensino na Saúde (Faculdade de Medicina da UFRGS, 20152017). Analista de Tecnologia da Informação na Universidade Federal do Rio Grande do Sul.

${ }^{(* *)}$ Graduada em Psicologia (PUCRS, 1992), Mestre em Psicologia Social e da Personalidade (PUCRS, 1994), Doutora em Psicologia (PUCRS, 2001) e com Pós-Doutorado em Psicologia UFRGS (2008) e em Psicologia ISCTE-IUL, Lisboa (2013). Professora Adjunta IV da Faculdade de Educação da UFRGS e Professora Permanente do Programa de Pós-Graduação Ensino na Saúde (Faculdade de Medicina UFRGS). Tem experiência em várias áreas, com ênfase em: Educação e Saúde, Psicologia, Religiosidade/Espiritualidade. Site: http://www.ufrgs.br/prescee.
} 
receptive to deal with religiosity / different spiritualities of his and perhaps unknown, considering the religious diversity in Brazil and up the multireligiousness (when the person attends more than one religion simultaneously).

KEYWORDS: Religiosity/Spirituality. Hospital setting. Health professionals. National Health Service. Brazil.

\section{INTRODUÇÃO}

O Brasil é um país reconhecidamente religioso e espiritualizado, embora os censos do IBGE de 1990, 2000 e 2010 tenham apontado aumento progressivo do número daqueles que se consideram sem religião. Esse percentual chegou aos $8 \%$, o que equivale a aproximadamente 15 milhões de pessoas, no censo de 2010 (ALTMANN, 2012). Os "sem religião" são as pessoas que não possuem vínculos de adesão a nenhuma religião, mas não necessariamente negam a existência de Deus ou de algo que considerem sagrado ou absoluto. Tanto que a população de ateus ficou em 615 mil, bem longe dos 15 milhões. Em comparação com outros países, também o Brasil aparece como um país de predominância religiosa. Esses números revelam que a religião é um tema de interesse para o brasileiro, que atravessa a cultura e se faz presente no cotidiano influenciando suas crenças, comportamento e visão de mundo.

Esses dados são confirmados pelo site The Arda (2015), que é uma associação que disponibiliza o escalonamento das religiões no mundo. A Coreia do Norte é o país com maior percentual de ateus, 15,6\%. Quando o tema é "Nações mais agnósticas", que não negam a existência de Deus, mas duvidam de sua existência, o Brasil apresenta 2,4\% da população nesse grupo. E o país com maior percentual de agnósticos é, mais uma vez, a Coreia do Norte (56,8\%).

A partir dessas constatações, pode-se inferir que a demanda para trabalhar as intersecções da Religiosidade e Espiritualidade (R/E) nos atendimentos de saúde pode ser maior do que o esperado e maior do que os profissionais de saúde estejam preparados para lidar. Pode-se indagar se esses profissionais têm algum aprendizado formal dentro das suas formações sobre o tema da R/E e o quanto estão receptivos para lidar com religiosidades/espiritualidades diferentes da sua e talvez desconhecidas, tendo em vista a diversidade religiosa no Brasil e até a multirreligiosidade (quando a pessoa frequenta mais de uma religião simultaneamente). O núcleo central da política de formação para a área da saúde se constitui pela própria população, nas suas necessidades sanitárias e de educação, procurando-se reconhecer e legitimar as realidades distintas locorregionais (CECCIM; FEUERWERKER, 2004). 
Se esse embate entre saberes/fazeres se dá no plano teórico, na prática, a vivência dessa dimensão religiosa/espiritual é multidimensional: no contexto clínico/hospitalar, o sujeito em tratamento não pode ser separado de suas dimensões cognitiva, afetiva, sociocultural, biológica, sob o risco de prejudicar o acolhimento e consequentemente proporcionar um cuidado menos integral. Nesse sentido a visão que se tem da pessoa, do paciente, do familiar como alguém que possui essa dimensão já é uma parte importante da prática do profissional em saúde. O enfrentamento da morte iminente, o medo do desconhecido, o receio de incapacidades físicas, são naturalmente vivências estressoras para o paciente e para a sua família. Nesse sentido, torna-se evidente a necessidade de entendimento e de um diálogo que inclua noções de $\mathrm{R} / \mathrm{E}$ a fim de que os profissionais de saúde possam fornecer uma terapêutica para aquele paciente específico, a partir de princípios que valorizem tanto os saberes médicos quanto as crenças do paciente. Isso é o que aponta a Política de Humanização do SUS ao referir o princípio da integralidade e ao adotar o modelo de que ao tratar o tema da saúde, se produz subjetividades (ALVES; JUNGES; LÓPEZ, 2010). Da mesma forma, é necessário que os profissionais tenham algum nível de conhecimento para orientar quando percebem que certas situações de cunho R/E não estão sendo terapêuticas, ou ainda, quando a $\mathrm{R} / \mathrm{E}$ pode ser um recurso positivo de enfrentamento.

De acordo com recentes estudos, pelo menos 90\% da atual população mundial está envolvida em alguma forma de prática religiosa ou espiritual, cujas evidências remetem para um importante papel em diversos aspectos da vida, sobretudo na saúde mental (MOREIRA-ALMEIDA; KOENIG; LUCCHETTI, 2014). Nos contextos hospitalares eclode uma demanda a partir do contato direto entre o paciente e o profissional da saúde. É esse o sujeito que vai problematizar o atual saber/fazer hegemônico, que, por séculos, vem fragmentando o doente, ora colocando-o numa posição de "alma-objeto" para a religião, ora ignorando e banalizando suas questões religiosas e espirituais, que são tomadas como fantasias e mitos, cuja escuta se torna negligenciada no tratamento.

Três revisões sistemáticas da literatura acadêmica identificaram mais de 3.0oo estudos empíricos em saúde e espiritualidade, cujos resultados, em geral, apontam que indivíduos que possuem maiores níveis de $\mathrm{R} / \mathrm{E}$ têm menos depressão, ansiedade, tentativas de suicídio e uso/abuso de substâncias, e experimentam uma melhor qualidade de vida, remissão mais rápida de sintomas depressivos, e melhores desfechos psiquiátricos (BONELLI; KOENIG, 2013; KOENIG; MCCULLOUGH; LARSON, 2001; KOENIG; KING; CARSON, 
2012). Dessa forma, a $\mathrm{R} / \mathrm{E}$ pode ser considerada como fator de proteção para o risco de várias morbidades e consequentemente como auxiliar no tratamento de saúde. Mas também há aspectos potencialmente danosos de vivência da $\mathrm{R} / \mathrm{E}$ por pacientes que é quando a religião não ajuda, mas sim causa danos como no caso do coping-religioso espiritual negativo (VEIT; CASTRO, 2013; JÖNSSON; LENCASTRE, 2016), por exemplo, o paciente pode adotar uma postura passiva frente ao tratamento, delegando a um ser superior a sua cura. Esses aspectos ainda são pouco explorados, sobretudo pela falta de atenção a essas temáticas, o que amplia a demanda por mais pesquisas nessa área.

A partir dessas reflexões, o presente trabalho tem por objetivo discutir a $\mathrm{R} / \mathrm{E}$ no contexto hospitalar, refletindo sobre estudos atuais e destacando os desafios, problematizações e também possibilidades da inclusão dessa temática nesse contexto. Reconhece-se a necessidade de discutir as intersecções do tema e de incluí-lo na formação profissional dos trabalhadores em saúde, porém são claras as dificuldades, paradoxos e desconhecimentos que envolvem tais considerações em vários contextos.

\section{APRESENTAÇÃO DOS TERMOS RELIGIOSIDADE, ESPIRITUALIDADE E RELIGIÃO}

Não se pode negar que mesmo com alguns avanços na inclusão dos temas da religião, religiosidade e da espiritualidade no âmbito científico, ainda há muitas divergências. Religião, religiosidade e espiritualidade têm sido, por vezes, vistas como sinônimos. Nesses casos, dificulta-se o entendimento, cabendo diferentes interpretações para uma mesma colocação, de forma que há espaço para um breve diálogo inicial a respeito dos conceitos.

A religião é considerada um fenômeno social que se configura por um conjunto de sistemas culturais e crenças, referindo-se à organização institucional de determinada forma de vivência religiosa. $\mathrm{O}$ construto pode abranger o sobrenatural, o não-natural, o teísmo, o deísmo, o ateísmo, o monoteísmo, o politeísmo e, em ambos os casos, divindades finitas e infinitas, caracterizando-se como a procura do sagrado que ocorre objetivamente por meio de práticas, cultos, ritos de forma institucional e compartilhada em grupo (KOENIG; KING; CARSON, 2012).

No que diz respeito à religiosidade, esta pode ser vista como a expressão do envolvimento com uma religião institucional, sendo uma manifestação da dimensão da espiritualidade. Conforme Alves et al. (2010, p. 431), ela também se refere "às formas pelas quais os símbolos religiosos são vivenciados e 
continuamente ressignificados, por meio de processos interativos concretos entre indivíduos e grupos”. Apresenta-se como pública, social e institucional, mas pode, igualmente, assumir uma vertente mais privada e individual, sendo que está associada a práticas religiosas cujo valor pode ser um fim em si mesmo ou não. Pode distinguir-se em religiosidade intrínseca e extrínseca: no primeiro caso, a pessoa vive a religião e, no segundo caso, a pessoa faz uso da religião para os seus próprios fins, geralmente objetivos mais mundanos (STROPPA; MOREIRA-ALMEIDA, 2008).

Ainda não há consenso a respeito do conceito de espiritualidade, podendo ser compreendida como um princípio de que há mais na vida além daquilo que podemos ver ou entender plenamente (MENDES, 2005). Embora a espiritualidade também possa ser vivenciada no contexto da religião, ela não se restringe a estes espaços, sendo experimentada fora das estruturas religiosas formais (ARRIEIRA et al., 2011).

Espera-se que a contribuição das variadas áreas da ciência possibilite uma visão global e integrada do fenômeno da espiritualidade propiciando uma compreensão mais integral do ser humano, enquanto ser complexo que é dotado de uma dimensão biopsicossocial, mas, também, espiritual. No presente trabalho, a abordagem utilizada será a da Religiosidade e Espiritualidade como um conceito integrado (R/E) a fim de facilitar o diálogo e suspender temporariamente o juízo a respeito dos conceitos, que, apesar de fazerem parte do trabalho, não constituem seu objetivo principal. Igualmente o uso do binômio visa enfatizar essa como uma ampla dimensão humana, una e indivisa que integra, sem dissociar, aspectos individuais e coletivos, privados e compartilhados, relativos à experiência direta do sagrado, mas também às práticas que levem a essas experiências.

\section{R/E NO CONTEXTO HOSPITALAR}

As origens do termo hospital remontam à Idade Média, cujo espaço de acolhida a doentes e peregrinos era conhecido como Hôtel-Dieu, incorporando em seu próprio nome, o caráter religioso da instituição. Como tal, passou por diversos movimentos de reorganização e atualização com os tempos, ao longo dos séculos e chega à atualidade, após o fortalecimento do racionalismo, com tensões entre ciência e religião, entre passado e presente. Naturalmente, essas constantes tensões produziram novas conformações, possibilitando reinvenções no cuidado à saúde. Porém, também é verdade que a ciência, como detentora de maior prestígio como geradora de conhecimento válido na atualidade, adotou, 
por longo tempo, uma postura de demérito em relação às religiões, negando os aspectos positivos que o entendimento/aceitação da R/E possa produzir nos pacientes. Entretanto, historicamente foram as comunidades religiosas que cuidaram dos doentes, desamparados, e moribundos de uma forma integrada e holística. Não apenas a religião perdeu espaço na medicina como o próprio paciente foi fragmentado nas suas várias dimensões e passou a ser tratado a partir de especialidades que pouco o observam na sua totalidade (KOENIG; KING; CARSON, 2012). Um exemplo dessa cisão se apresenta na atenção à dor, cuja conceituação no ocidente surge a partir do dualismo cartesiano em que corpo-mente-espírito são vistos dissociados entre si. Essa visão prejudica a compreensão integrada do ser humano, sobretudo em relação à experiência da dor, por ser esta uma vivência individual, mediada por vários componentes biológicos, afetivos, cognitivos, sociais e comportamentais (MARQUES; SILVA, 2014).

Sendo o contexto hospitalar um lugar de alta complexidade e de constante enfrentamento de variados desafios, assume-se que, ao abrir a possibilidade de respeitar o sujeito na sua integralidade, a compreensão da dimensão da $\mathrm{R} / \mathrm{E}$ torna-se imprescindível. Dessa forma, um hospital não pode prescindir de regulamentações e atividades incorporadas no seu fluxo cotidiano que prevejam o acolhimento dessa demanda. Sendo uma organização composta por múltiplos níveis, plural em atendimentos, deve estar ciente das problematizações sociais, bem como de suas demandas. Há que se ampliar o escopo de atuação, rumo a uma mudança paradigmática para além do modelo biomédico incluindo uma abordagem holística voltada para a qualidade de vida (CASTILHO; CARDOSO, 2015).

O cuidado em saúde no contexto hospitalar brasileiro está face-a-face com esse público que valoriza e vivencia a $\mathrm{R} / \mathrm{E}$ nas suas vidas, bem como com aqueles que, frente a situações graves e estressantes, irão recorrer ao coping religioso-espiritual ${ }^{1}$. O fato de o estado brasileiro ter adotado uma forma laica e secular de abordar a saúde, não torna os brasileiros a-religiosos. Apesar da laicidade que deve ser seguida pelos serviços públicos, deve-se evitar o excessivo laicismo que seria não reconhecer o direito das pessoas em manifestar a sua $\mathrm{R} / \mathrm{E}$ publicamente. Usada de forma equilibrada e integrada a outras dimensões, a R/E pode auxiliar na prevenção de doenças, em melhores desfechos, a ajudar no enfrentamento e proporcionar apoio e encorajamento (KLIEWER, 2004).

$1 \mathrm{O}$ coping religioso-espiritual é a forma como a pessoa utiliza sua fé religiosa e/ou espiritual para lidar com o estresse e os problemas de vida (WONG-MCDONALD; GORSUCH, 2000). 
Outra vertente de compreensão da inserção da R/E no contexto hospitalar é o aspecto organizacional do hospital, em que essa dimensão pode auxiliar funcionários e gestores a encontrar um significado mais profundo - e melhores recompensas - por meio do local de trabalho (LAABS, 1995). Nesse sentido, relaciona-se aos funcionários do hospital, como entidades com necessidades espirituais, que desejam experimentar um sentido de propósito e de significado no seu trabalho e que pretendem experimentar um sentido de conexão com outras pessoas e com a sua comunidade de trabalho (ASHMOS; DUCHON, 2000). Todas as instituições, independentes do tipo de serviço ou produção, podem e devem provocar questões reflexivas e existenciais no seu público interno, estimulando uma visão panorâmica da dos processos de saúde e doença, vida e morte.

Nesse contexto, a R/E não está ligada a um sistema religioso específico, mas sim a um compromisso com a dimensão espiritual das pessoas e propõe uma forma mais humanizada no tratamento pessoal, impulsionando a autorrealização e o respeito à pluralidade religiosa. Embates entre distintas religiões no mundo atravessam o tempo e distâncias, produzindo e provocando desacomodações no contexto das microrrelações. Estas, a seu turno, podem desestabilizar os trabalhos em equipe, trazendo não apenas dificuldades gerenciais, mas também comprometendo o próprio trabalho em saúde. Há que se problematizar o fazer na instituição, seja ele o trabalho do gestor ou do profissional de saúde, a fim de que a $\mathrm{R} / \mathrm{E}$ saiam da invisibilidade e possa contribuir na humanização do atendimento.

Essa inserção vem sendo paulatinamente lembrada por organismos internacionais, como a Organização das Nações Unidas, que consideram os elementos espirituais nos cuidados paliativos como prioridade quando a doença não mais responde a tratamentos curativos (BRASIL, 2001). Por meio da identificação de dificuldades e possibilidades da integração da espiritualidade nos serviços de saúde será possível planejar ações mais concretas, buscando uma prática mais humanizada e sensível às crenças dos pacientes e com mais saúde também para os profissionais que trabalham com estes. Busca-se, assim, uma relação profissional-usuário onde os sujeitos sejam parceiros e aliados na produção de saúde. Alguns centros de saúde têm investido na criação de espaços físicos para acolher o diálogo religioso ou mesmo serviços hospitalares como, por exemplo, a capelania, cujo objetivo é dar conta dessa dimensão. O Grupo Hospitalar Conceição, em Porto Alegre, que é uma referência nacional para a humanização, contempla em sua estrutura hospitalar um espaço inter-religioso 
no qual lideranças de diferentes religiões podem dialogar com seus fiéis (ALVES; JUNGES; LÓPEZ, 2010).

\section{A INCLUSÃO DA R/E NA FORMAÇÃO PROFISSIONAL}

A ausência do tema na formação dos profissionais de saúde provavelmente é devido à destituição da $\mathrm{R} / \mathrm{E}$ de um lugar junto às práticas médicas: um fenômeno observado a partir da incursão radical da medicina no positivismo científico e na tentativa de união de ciência e prática baseada em evidências, mais notabilizada na sociedade ocidental. Estima-se que essa cisão tenha ocorrido no século XVI com o advento da revolução científica e a emergência do método científico (KLIEWER, 2004). A construção do conhecimento levada a cabo pela racionalidade científica, além de possibilitar um notável desenvolvimento de uma medicina eminentemente técnica, também polarizou e fragmentou o entendimento do sujeito enquanto ser complexo e multidimensional, esquadrinhando o mesmo em órgãos e tecidos (FOUCALT, 1979). Foucault localiza o nascimento da Clínica no findar do século XVIII, quando o discurso emergente da racionalidade anátomo-clínica começa a reconfigurar a medicina moderna, transformando a organização de seu conhecimento e sua prática, pautados agora em um presumido empirismo que a coloca no glorioso lugar de disciplina científica. Nesse contexto, houve uma significativa mudança: seu objeto de investigação passa a ser a doença ou o corpo do ser que adoece, fundamentados sob um olhar positivo e inseridos num discurso redutivista daquilo que está alocado numa subjetividade dos sintomas. A clínica instaura-se no lugar de justamente da aplicação de um olhar e saber (médico e científico) sobre a doença, que assim lhe confere objetividade (FOUCAULT, 1963).

Por vários séculos a apropriação incauta do cuidado pela religião, cujo principal objetivo era o de conseguir uma "salvação espiritual" ao sujeito, fez emergir uma reação inconciliável entre o cientificismo pragmático e o saber religioso/espiritual, de forma que a tensão entre esses saberes permaneça atuante e, por vezes, incapacite um diálogo construtivo.

Até recentemente, esses temas não eram incluídos no currículo de profissionais de saúde, nem tinham lugar na prática clínica hospitalar de forma consistente e ética. Mas isso tem se alterado e o cuidado holístico tem se tornado um tema corrente nos programas de educação para a saúde (LUNDBERG; KERDONFAG, 2010) o que abre um campo também para a inclusão da R/E. Nos últimos vinte anos, com a publicação de várias centenas de 
artigos científicos na área médica e psicológica sobre a relação entre religião e saúde, muitas escolas médicas já têm começado a integrar questões sobre R/E aos seus currículos. Nos Estados Unidos, 84 das 126 escolas médicas oferecem cursos sobre espiritualidade e medicina. No Brasil, iniciativas pioneiras de oferecimento de disciplinas sobre medicina e espiritualidade partiram das Faculdades de Medicina da Universidade Federal do Ceará e da Universidade Federal de Minas Gerais (STROPPA; MOREIRA-ALMEIDA, 2008). Além disso, com base nessas recentes evidências empíricas, muitas organizações internacionais de profissionais da área da saúde têm apontado para o cuidado com a R/E como um importante componente da saúde do paciente, e que os profissionais deveriam integrar a prática clínica e hospitalar. Em se tratando de saúde mental, importantes organizações internacionais têm dado espaço e criado seções dedicadas especialmente a R/E (CAVALHEIRO; FALCKE, 2014). Apesar disso, quando se refere à $\mathrm{R} / \mathrm{E}$ de psicólogos, um estudo recente mostrou que, em relação à população em geral, esse profissional tem menor espiritualidade. Esses dados parecem indicar que o curso de psicologia contribui para o declínio da espiritualidade, provavelmente por sofrer influência da vertente psicanalítica (em especial no sul do Brasil) e por considerar que a psicologia enquanto saber científico deve se omitir de explorar o tema da R/E. Sem aprofundar a temática, ressalta-se aqui a possibilidade de que a concepção psicanalítica de religiosidade, como um aspecto essencialmente negativo, ainda esteja sendo amplamente transmitida, sem que se possa abrir o diálogo para um posicionamento crítico e transversalizado sobre o tema:

Tal postura merece questionamento para que a irredutibilidade e o cerceamento dogmático das instituições religiosas, devidamente combatidos pela psicanálise, não acabem sendo reproduzidos em sua própria concepção diante da inteireza das dimensões humanas e, assim, da espiritualidade. (CAVALHEIRO; FALCKE, 2014, p. 42).

A despeito das dificuldades de interlocução, parece inquestionável a importância de legitimar um lugar à R/E no contexto hospitalar e na formação dos profissionais de saúde. Entretanto, grandes desafios são apresentados quando se pensa em como incorporar e implementar nas práticas profissionais esse reconhecimento, a partir de referenciais e saberes variados que sejam científicos, laicos e também oriundos da cultura e tradição local. Muitos profissionais de saúde não consideram os assuntos R/E como parte de seus trabalhos, não entendem por que o deveriam ser, não sabem nem como nem quando introduzi-los e sequer imaginam quais seriam os resultados caso os 
incluíssem (MARR; BILLINGS; WEISSMAN, 2007). Embora seja nítida a presença de elementos espirituais nos contextos hospitalares, especialmente as necessidades e demandas dos pacientes, alguns profissionais de saúde não se sentem treinados para tanto. Outras barreiras também estão presentes, como a falta de tempo ou de recursos, pouca privacidade e atitudes pessoais por parte do profissional, inclusive algum desconforto por adentrar num tema tido socialmente como privado (LIND; SENDELBACH; STEEN, 2011). Especialmente em relação à psicologia, há que se legitimar a espiritualidade na esfera científica, incorporando-a na formação acadêmica desse curso. É preciso revisar e reformular paradigmas norteadores da ciência psicológica, cuja dimensão inerente ao humano e sua contribuição à saúde psíquica tem sido negligenciada. $O$ percurso vivenciado durante a formação acadêmica em psicologia parece estar contribuindo para o embotamento da espiritualidade dos próprios psicólogos, ao adotarem rigorosamente suas doutrinas psicológicas (CAVALHEIRO; FALCKE, 2014). E pode-se imaginar que nas outras áreas o mesmo possa ocorrer.

DESAFIOS DO TRABalho DO PROFISSIONAL DE SAÚdE COM A R/E DO PACIENTE

O termo da integralidade tem sido apontado nas discussões científicas como uma ideia de superar o entendimento fragmentário do ser humano. No Brasil, este termo passa a ter relevância entre as décadas de 70 e 80, ganhando destaque e norteando política de Estado, e procurando "valorizar a subjetividade humana, ofertando a possibilidade para o diálogo e a inserção das diversas formas de ação em saúde" (CASTILHO; CARDOSO, 2015). Um dos grandes desafios para integrar espiritualidade e cuidado espiritual nos currículos e na prática hospitalar tem sido a compreensão evolutiva do conceito de espiritualidade, que passa a ser entendida como algo mais amplo do que a religião, sem excluí-la (DEZORZI; CROSSETTI, 2008). Embora um conceito de religiosidade ou de espiritualidade possa ser elaborado e definido, dificilmente será aplicável a todos os contextos, faixas etárias, etnias, etc. Neste artigo há ênfase no que a religiosidade tem em comum com a espiritualidade e unindo os dois termos em um só, religiosidade/espiritualidade, considerando uma ampla dimensão que inclui aspectos religiosos e também os existenciais ou laicos servindo ao que quer que o público trate como dita dimensão. Entretanto, há grupos que consideram o espiritual como sendo outro reino ou um universo paralelo cujas curas milagrosas põem em dúvida o arsenal da medicina 
tradicional. Esse pode ser um aspecto bastante controverso no qual os grupos de bioética hospitalares têm se dedicado, especialmente quando pacientes e famílias geram um antagonismo entre a medicina tradicional e as curas espirituais.

A assistência espiritual ou a integração da experiência religiosa do paciente aos cuidados em saúde carece de sistematização prática fundamentada e de lugar institucional. Requer sair da situação de práticas desconectadas e ainda não reconhecidas ou autorizadas institucionalmente, para formarem um mosaico consistente, diverso, mas integrado, de ações e possibilidades junto aos pacientes e seus familiares, em consonância com as políticas de humanização do SUS (BRASIL, 2007). Além de maior desenvolvimento técnico proveniente de um volume consistente de estudos e publicações na área, há também habilidades humanas a serem forjadas nos profissionais para que possam acolher e escutar de forma qualificada as demandas dos pacientes, não somente físicas, mas também espirituais.

Na visão da integralidade da atenção como um esforço da equipe de saúde de traduzir e atender, da melhor forma possível, as necessidades de saúde, sempre complexas, captadas em sua expressão individual (CECÍLIO; PINHEIRO; MATTOS, 2001), identifica-se a importância de uma formação e instrumentalização dos profissionais junto a uma adequação dos serviços de saúde a fim de que essas ações sejam institucionalizadas e ofereçam condições mais adequadas para o acolhimento à religiosidade de seus usuários e respectivos familiares, bem como uma melhor orientação e integração dessa dimensão no cuidado em saúde. Igualmente, é importante ressaltar a importância da compreensão dessa dimensão na vida pessoal e profissional dos trabalhadores em saúde como autocuidado.

Além do desafio de conceitualizar a $\mathrm{R} / \mathrm{E}$, é necessário desenvolver uma sistemática de aplicação do conceito que dê conta das diversas realidades e contextos; e ainda outros desafios estão presentes. Por exemplo, o quanto a R/E pode ser danosa (os chamados red flags, ou sinais de alerta, que são os aspectos controversos e potencialmente danosos da vivência religiosa/espiritual para o paciente internado). Considerando que nas áreas humanas lidamos com questões complexas de difícil controle, também o tema da $\mathrm{R} / \mathrm{E}$ não é uma prescrição absolutamente confiável. Embora inúmeros estudos apontem as associações positivas entre saúde e R/E, muitos outros casos também surgem de risco de prejuízos pessoais, baixa resolutividade de conflitos, coping negativo, culpa, abalo da fé, etc. (PERES et al., 2007). 


\section{POSSIBILIDADES DA INSERÇÃO DA R/E NO CONTEXTO DO SUS}

No contexto brasileiro, o tema da integralidade tornou-se evidente em meados de 1970 a 1980 com o advento do Movimento da Reforma Sanitária (BERNARDES, 2011). Em um estudo documental que investigou 67 políticas públicas de saúde publicadas, as autoras (CASTILHO; CARDOSO, 2015) procuraram pelos termos "espiritualidade", "religiosidade" e "religião" e encontraram sua presença, mas numa abordagem sutil e não explicativa, e sugerem uma ampliação da discussão. Os termos apareceram nas políticas principalmente na importância de se atentar para essa dimensão no cuidado em saúde no que se refere a: respeitar diversidades religiosas, povos e culturas com peculiaridades religiosas, direito de crença pessoal e direito à manifestação religiosa. Entretanto, consideraram insipiente e pouco consistente a forma de abordá-lo. Mas vendo esse estudo sobre outro ângulo, o qual as autoras não consideraram, há uma nítida indicação por parte dessas políticas de se considerar esses âmbitos como partícipes do cuidado em saúde e da compreensão do ser humano na sua integralidade. Tanto nos termos humanização, acolhimento e saúde integral, quanto na valorização do contato com o usuário, nas práticas dialógicas e nos processos de subjetivação, pode-se depreender a presença das múltiplas dimensões humanas, tanto do usuário quanto do profissional, a saber, a R/E.

A criação da Política Nacional de Práticas Integrativas e Complementares (PNPIC) no SUS em 2006 aparece como uma garantia à integralidade nas ações em saúde. O Ministério da Saúde publicou a Portaria $n^{0}$ 971, instituindo a PNPIC no SUS, que faculta novas abordagens de intervenção (BRASIL, 2006). Essa política veio especialmente a atender às orientações da Organização Mundial da Saúde, sobretudo, à necessidade de se conhecer, apoiar, incorporar e implementar experiência no âmbito das referidas práticas. A PNPIC abrange a Medicina Tradicional e Complementar/Alternativa como as terapias medicamentosas com uso de fitoterapia (compostos orgânicos oriundos em parte de animais e/ou minerais), e não-medicamentosas terapias manuais e/ou espirituais (WORLD HEALTH ORGANIZATION, 2001).

A PNPIC mostra como essa ampliação do escopo de atuação e na maneira de conceber o usuário, não trata de ignorar a terapêutica tradicional, mas sim de complementar em direção a resultados positivos e bem-sucedidos. A indicação é no sentido de problematizar a experiência contemporânea cuja condução no aspecto biomédico, por vezes, tem levado a um radicalismo pragmático, em um processo que vem sendo apontado como “medicalização da vida”. Há que se ir 
além e pensar que os tratamentos convencionais têm sido eficientes em grande parte, mas também apresentam condições negativas para o paciente, como os efeitos colaterais, dificuldades de lidar com certas doenças e restabelecer o equilíbrio do organismo como um todo e no seu contexto.

As poucas iniciativas de diálogo com as práticas alternativas em saúde, deslegitimadas pelo saber científico por trazerem aspectos transcendentais (considerados comumente como sem validade científica), põem de lado uma possível conjugação de esforços. As práticas alternativas, sobretudo as que provêm historicamente de sociedades orientais, tradições espirituais e filosóficas, se baseiam em princípios de promoção do equilíbrio e saúde, em vez de atacarem a doença e a morte. Mas, na medida em que elas se abrem a outros critérios, como a intuição ou a fé, que são vistos como atitudes suspeitas pela biomedicina ocidental, elas correm o risco de serem desacreditadas. Aquelas que conseguem construir um discurso técnico relativamente coerente como a homeopatia ou acupuntura são "toleradas". Mas as que fazem apelo mais forte a elementos ditos “mágicos” são vistas com suspeição por extrapolarem os limites da racionalidade instrumental e laica predominante no seio do campo oficial. Assim, as ações em saúde têm perdido sua dimensão cuidadora e, apesar dos contínuos avanços científicos, elas têm perdido potência e eficácia.

Grande parte desse poder perdido provém da relação empobrecida em que o paciente/usuário é tomado como simples corpo biológico e objeto da ação, tornando-o refém de apenas um único modelo de tratamento de saúde: o biomédico. A relação que se estabelece entre o suposto saber médico e o usuário acaba sendo vertical, unidirecional, como se prescindisse da ação/cooperação de quem está sendo "tratado". Ou ainda, como se a cooperação fosse obtida automaticamente a partir da "iluminação" técnica sobre o problema e as condutas prescritivas para enfrentá-lo. Mas o cientificismo não tem resolvido todos os problemas e, na prática, tem se perdido a participação e o empoderamento do usuário que tem limitada aderência aos tratamentos, sobretudo nas afecções crônicas.

Em uma recente pesquisa sobre práticas contemplativas aplicadas a pacientes com dor crônica no contexto do Sistema Único de Saúde (SUS) do Brasil, resultados parciais permitiram indicar que essa prática é totalmente viável de ser inserida como complementar ao tratamento tradicional e alopático. Também nesse trabalho, a partir de relatos dos participantes e das respostas nos questionários, observou-se a melhora da atenção ao longo do processo, juntamente a melhores possibilidades de lidar com a dor e uma maior autoconsciência por parte dos pacientes (MARQUES; SILVA, 2014). Muitas 
práticas consideradas alternativas dialogam com crenças e valores do próprio paciente, sensibilizando para uma melhor escuta e acolhimento ao usuário, que passa a aderir ao tratamento proposto e melhorar as práticas de autocuidado, repercutindo em melhora geral da saúde.

\section{CONSIDERAÇÕES FINAIS}

Tratando-se de um tema indissociado da constituição das sociedades, considerado muitas vezes a motivação de guerras e arbitrariedades, mas também de inúmeras realizações e benefícios, a $\mathrm{R} / \mathrm{E}$ é tema que aparece no cotidiano dos hospitais, desacomodando instituições, profissionais de saúde, gestores e pacientes. A problematização desse assunto, para além de apenas uma aposta, é uma necessidade que aponta para a legitimação do debate, mesmo quando da sua discordância, podendo e devendo ser integrado nas práticas em saúde. $\mathrm{O}$ que interessa é que a $\mathrm{R} / \mathrm{E}$ possa se tornar visível $\mathrm{e}$ interpelada no cotidiano do contexto hospitalar, dentro de uma abordagem que vise contemplar o indivíduo em sua integralidade (dimensões física, social, mental e espiritual) e instrumentalizar os profissionais de saúde a lidar com as diferenças, dentro dos princípios da ética que norteiam um melhor cuidado. Fundamental para isso é a participação da população no desenvolvimento das políticas públicas cuja representação fortalece os aspectos da diversidade em direção à produção do cuidado integral mais efetivo.

Acredita-se ainda na relevância de pesquisas que investiguem o reflexo dessa abordagem nas ações cotidianas em diferentes contextos de gestão e produção do cuidado em saúde.

Considera-se esse trabalho como disparador para futuros aprofundamentos na gestão do cuidado em saúde no contexto hospitalar, em discussões que apontem para a inclusão da R/E na formação dos profissionais de saúde, em futuras pesquisas que indiquem os desafios do trabalho desses profissionais junto aos pacientes e as formas que se possa inserir a R/E no contexto do SUS.

\section{REFERÊNCIAS}

ALTMANN, Walter. Censo IBGE 2010 e Religião (IBGE 2010 Census and Religion).

Horizonte - revista de Estudos de Teologia e Ciências da Religião da

Pontifícia Universidade Católica de Minas Gerais, v. 10, n. 28, p. 1122-1129.26 
out./dez. 2012. Disponível em: <http://periodicos.pucminas.br/index.php/horizonte/ article/view/4165>. Acesso em: 2 jul. 2015.

ALVES, Joseane de Souza; JUNGES, José Roque; LÓPEZ, Laura Cecília. A dimensão religiosa dos usuários na prática do atendimento à saúde: percepção dos profissionais de saúde. O Mundo da Saúde, v. 34, n. 4, p. 430-436, 2010.

ARRIEIRA, Isabel Cristina De Oliveira et al. Espiritualidade na equipe interdisciplinar que atua em cuidados paliativos às pessoas com câncer. Ciência, Cuidado e Saúde, v. 10, n. 2, abr./jun. 2011. Disponível em: <http://periodicos.uem.br/ojs/index.php/ Cienc CuidSaude article/view/15689>. Acesso em: 19 ago. 2016.

ASHMOS, D. P.; DUCHON, D. Spirituality at Work: a conceptualization and measure. Journal of Management Inquiry, v. 9, n. 2, p. 134-145, jun. 2000. [Disponível em: < http://ejournal.narotama.ac.id/files/ProQuest_54883215.pdf>.] Acesso em: 2 jul. 2015 .

BERNARDES, Elexandra Helena. Sentidos de integralidade produzidos com trabalhadores de saúde em relações grupais. 2011. Tese (Doutorado), Universidade de São Paulo, Escola de Enfermagem de Ribeirão Preto. Ribeirão Preto, 2011.

BONELLI Raphael M.; KOENIG Harold G. Mental disorders, religion and spirituality 1990 to 2010: a systematic evidence-based review. Journal of Religion and Health. v. 52, issue 2, p. 657-673, doi: 10.1007/s10943-013-9691-4, Jun. 2013.

BRASIL, Ministério da Saúde. Carta dos direitos dos usuários da saúde. Ilustrada. Brasília, DF: Editora MS, 2007.

BRASIL, Ministério da Saúde. Cuidados paliativos oncológicos: controle da dor. [S.l.]: INCA, 2001. Disponível em: <http://www.inca.gov.br/publicacoes/manual_dor.pdf>. Acesso em: 14 jul. 2015.

BRASIL. Portaria $n^{\circ}$ 971, de 03 de maio de 2006: Aprova a Política Nacional de Práticas Integrativas e Complementares (PNPIC) no SUS. Diário Oficial da União, 2006. [Disponível em: <http://www.ins.gob.pe/repositorioaps/o/7/jer/censi_med_norm/ BRA-Portaria\%20971-2006.pdf>. Acesso em 04 dez. 2016.]

CASTILHO, Carolina Nantes De; CARDOSO, Paula Tatiana. Espiritualidade, religiosidade e religião nas políticas públicas de saúde: um olhar para a integralidade. Revista Família, Ciclos de Vida e Saúde no Contexto Social, v. 3, n. 1, 2015.

CAVALHEIRO, Carla Maria Frezza; FALCKE, Denise. Espiritualidade na formação acadêmica em psicologia no Rio Grande do Sul. Estudos de Psicologia (Campinas) v. 31, n. 1, p. 35-44, jan./mar., 2014. [Disponível em: http://www.scielo.br/scielo.php? script $=$ sci_arttext\&pid=S0103-166X2014000100004]. Acesso em: 2 jul. 2015.

CECCIM, Ricardo Burg; FEUERWERKER, Laura C. M. O quadrilátero da formação para a área da saúde: ensino, gestão, atenção e controle social. Physis: Revista de Saúde Coletiva, v. 14, n. 1, 2004. Disponível em: <http://www.scielo.br/scielo.php? script $=$ sci_arttext\&pid $=$ So103-73312004000100004\&lng $=$ pt\&nrm $=$ iso\&tlng $=$ pt $>$. Acesso em: 2 jul. 2015. 
CECÍLIO, L. C. de O.; PINHEIRO, R; MATTOS, Araújo, R. As necessidades de saúde como conceito estruturante na luta pela integralidade e equidade na atenção em saúde. Os sentidos da integralidade na atenção e no cuidado à saúde, v. 1, Rio de Janeiro, IMS Abrasco, 2001.

DEZORZI, Luciana Winterkorn; CROSSETTI, Maria da Graça Oliveira. Spirituality in self-care for intensive care nursing professionals. Revista Latino-Americana de Enfermagem v. 16, n. 2, p. 212-217, mar./abr. 2008. [Disponível em: < http://www. scielo. br/pdf/rlae/v16n2/o7.pdf>]. Acesso em: 2 jul. 2015.

FOUCALT, Michel. Microfísica do poder. Rio de Janeiro: Graal, 1979.

FOUCAULT, M. O nascimento da clínica. 5. ed. Tradução de Roberto Machado. Rio de Janeiro: Forense Universitária, 1998.

KLIEWER, Stephen. Allowing spirituality into the healing process. The Journal of Family Practice, PMID: 15298831, v. 53, n. 8, p. 616-624, ago. 2004.

KOENIG Harold G.; MCCULLOUGH Mike E.; LARSON David B. Handbook of religion and health. New York: Oxford University Press, 2001.

KOENIG, Harold G.; KING, Dana E.; CARSON, Verna Benner. Handbook of religion and health. 2 ed. Oxford-New York: Oxford University Press, 2012.

JÖNSSON, Catherina; LENCASTRE, Leonor. Trauma e Religião: um modelo de adaptação psicológica baseado no coping religioso. Psicologia, Saúde e Doenças, v. 17, n. 1, 2016.

LAABS, Jennifer J. Balancing spirituality and work. Personnel Journal, v. 74, n. 9, p. 60-77, 1995 .

LIND, Bradley; SENDELBACH, Sue; STEEN, Sue. Effects of a spirituality training program for nurses on patients in a progressive care unit. Critical Care Nurse PMID: 21632597, v. 31, n. 3, p. 87-90, jun. 2011.

LUNDBERG, Pranee C; KERDONFAG, Petcharat. Spiritual care provided by Thai nurses in intensive care units. Journal of Clinical Nursing, v. 19, n. 7-8, p. 11211128 , abr. 2010. Acesso em: 2 jul. 2015.

MARQUES, Luciana Fernandes; SILVA, Janete Mengue Da. Práticas contemplativas aplicadas a pacientes com dor crônica no SUS. 2014, Curitiba, Brasil. Anais... Curitiba, Brasil: [s.n.], 2014.

MARR, Lisa; BILLINGS, J. Andrew; WEISSMAN, David E. Spirituality training for palliative care fellows. Journal of Palliative Medicine PMID: 17298265, v. 10, n. 1, p. 169-177, fev. 2007.

MENDES, João Manuel Galhanas. Como inserir a espiritualidade no processo terapêutico. Revista Servir, v. 54, n. 4, p. 158-164, 2005.

MOREIRA-ALMEIDA, Alexander; KOENIG, Harold G.; LUCCHETTI, Giancarlo. Clinical implications of spirituality to mental health: review of evidence and practical guidelines. Revista Brasileira de Psiquiatria, v. 36, n. 2, p. 176-182, abr. 2014. Acesso em: 2 jul. 2015 . 
PERES, Mario F. P. et al. A importância da integração da espiritualidade e da religiosidade no manejo da dor e dos cuidados paliativos. Revista de Psiquiatria Clínica, v. 34, p. 82-87, 2007. Acesso em: 2 jul. 2015.

STROPPA, André; MOREIRA-ALMEIDA, Alexander. Religiosidade e saúde. Saúde e espiritualidade: uma nova visão da medicina. Belo Horizonte: Inede, p. 427443, 2008.

VEIT, Carina Maria; CASTRO, Elisa Kern de. Coping religioso/espiritual em mulheres com câncer de mama. Arquivos Brasileiros de Psicologia, v. 65, n. 3, p. 421-435, 2013 .

WONG-MCDONALD, Ana; GORSUCH, Richard L. Surrender to God: an additional coping style? Journal of Psychology and Theology, v. 28, n. 2, p. 149, 2000.

WORLD HEALTH ORGANIZATION. General guidelines for methodologies on research and evaluation of traditional medicine. [S.l.]: World Health

Organization, 2001.

Recebido em 15/o8/2016 Aprovado em 17/11/2016 